\title{
Creating a Professional Development Plan for a Simulation Consortium
}

Pamela R. Jeffries PhD, RN, ANEF, FAAN; Jim Battin, BS; Michelle Franklin, RN, MSN; Rhonda Savage, MPH, BS, BA; Hollace Yowler, MSN, RN; Caroline Sims, RN, Doctoral Candidate; Tamara Hall, MSN, RN; Shelly Eisert, MSN, MHA, RN, CNE; Cynthia Lauber MSN, RN, FNP; Stephanie Brown, MEd, BSN, RN, CPN; Karen Werskey, BSN, RN, CNOR; Rebecca J. Bartlett Ellis, RN, Doctoral Candidate; Terri Everage, RT; Laurie Dorsey, MSN, RN

\begin{abstract}
As the United States struggles with health care reform and a nursing education system that inadequately prepares students for practice, dramatic advances in educational technology signal opportunities for both academic and practicing nurses to affect our profession as never before. Simulation technologies provide large and small institutions with the means to educate health care students and novice professionals effectively and efficiently through hands-on experience, but the costs of such a venture can be prohibitive. A simulation consortium offers a venue for different health care and educational institutions with shared goals to pool knowledge, monies, and labor toward health care education throughout a geographic area. This article details one Midwestern U.S. region's work in creating a professional development plan for a new simulation consortium.
\end{abstract}

\section{Keywords}

Administering a consortium, Collaborative process, Designing a consortium, Education consortium, Professional development, Simulation collaboration, Simulation consortium, Simulation network, Superusers, Workforce development

This is the author's manuscript of the article published in the final edited form as:

Jeffries, P. R., Battin, J., Franklin, M., Savage, R., Yowler, H., Sims, C., ... Dorsey, L. (2013). Creating a Professional Development Plan for a Simulation Consortium. Clinical Simulation in Nursing, 9(6), e183e189. https://doi.org/10.1016/j.ecns.2012.02.00 


\section{Background}

In 2002, community and health care leaders in a Midwestern region began addressing the effects of a nursing shortage in the area. Representatives from the Community Education Coalition, a community college, a large state university, a large regional tertiary care center, a regional hospital, and the Commission on Higher Education met to discuss the impending labor shortage, especially in practical and registered nursing. They decided to quantify the shortages by developing a more accurate picture of current vacancy rates in regional hospitals and extended care facilities. A survey of hospitals and extended care facilities showed that the region had a vacancy rate of $8 \%$ in registered nursing occupations that, if immediate action was not taken, would increase to $24 \%$ by 2008 . At that time, the large university in the region was granting only 20 associate's degrees in nursing each year. The community college did not have an associate's degree program in nursing at that time. During 6 months, hospital, education, and community leaders managed to raise more than \$1 million (in cash and in-kind

donations) to expand the associate's degree in nursing opportunities in the region, including establishing a program at the community college and strengthening the university's program for mobility from associate to bachelor of science in nursing (BSN).

To organize efforts toward this initiative, the Community Education Coalition convened a Southeast Indiana Hospital and Education Consortium (see Figure 1), which met quarterly to establish goals, monitor actions, and report progress. That consortium raised an additional $\$ 586,000$ through state grants toward increasing faculty positions to support the growth of nursing student enrollment. During the next 4 years, the collaborative effort resulted in an increase in graduates with an associate's degree in nursing, totaling 104 in 2007. In addition, the RN-to-BSN mobility program had its first graduating class of 11 students in 2007. Enrollment has continued to increase in both programs, to a total of 210 graduates with associate's degrees and 35 BSN graduates in 2010.

In 2005, Indiana Workforce Development (2005) initiated a program called Strategic Skills Initiative (SSI). SSI provided the opportunity to take a closer look at highly in-demand and highly compensated occupations within each Economic Growth Region in the state. In southeast Indiana, Economic Growth Region 9 comprised 10 counties. Regional community and health care educators were provided demographic information on key industry sectors within the region. The data revealed that the health care sector was the second-largest sector in the region and employed $10.7 \%$ of the workforce, or 14,287 
people. SSI provided the impetus to organize action plans regionally and develop a consortium of health care educators.

The Southeast Indiana Healthcare Consortium was formed in 2008 as part of a regional grant and program called Economic Opportunities for $2015\left(\mathrm{EcO}_{15}\right)$. The health care segment of $\mathrm{EcO}_{15}$ aims to ensure patient safety and outcomes by improving the quantity and quality of health care professionals through better health care education. The consortium was made up of educators and leaders from seven hospitals, five postsecondary educational institutions, and two career technical education centers that represented 29 high schools within the region (Figure 1 identifies the major institutions involved). The three main goals of the health care consortium include (a) developing the infrastructure for the use of simulation methodology in the education system, (b) increasing the supply of nursing graduates in the region, and (c) providing coordination through the development of a regional health care network of partners.

Representatives from participating organizations met regularly during 4 months to complete several important strategic planning steps: (a) develop a vision for the use of simulation methodology in educational practices; (b) complete assessment of strengths, weaknesses, opportunities, and threats in current simulation practice; (c) develop key core strategies; and (d) develop a project plan, budget, milestones, and activities required to implement a successful project. The core strategies focused on developing a plan for professional development in simulation education, standardizing scenario development, sharing scenarios through a regional library, providing reliable technical support for clinical simulation operations, and improving critical thinking skills through the use of evidence-based practices.

\section{Literature Review}

\section{Consortium Organization and Development}

To advance the nursing profession and address the multitude of challenges facing the health care system today, strong partnerships are necessary (Tornabeni \& Miller, 2008). Strategic partnerships help stakeholders meet today's education and practice challenges in health care (Nickitas, 2008). A consortium, which Articola (1998) defines as "an alliance of like agencies that come together to jointly offer services or products to the customer," provides many benefits to different groups that share a common purpose (p. 112). Consortia allow stakeholders the opportunity to collaborate, generate 
innovative ideas, reduce costs, and address common concerns with shared resources (Seropian, Driggers, Taylor, Gubrud-Howe, \& Brady, 2006). In addition, the collaborative opportunities afforded by consortia enhance the efforts and abilities for continued program development and growth (Kost, Wildgust, \& Woods, 2010).

The significant financial demands of establishing a simulation program provide a great impetus for consortium building. Both education and health care professionals have identified cost-effectiveness and quality as key concepts, and an educational consortium enables resources and expertise to be shared among stakeholders in a fiscally conservative manner (Articola, 1998). Additionally, collaboration among consortium stakeholders is particularly beneficial when resources are scarce (Maas, Conn, Buckwalter, Herr, \& Tripp-Reimer, 2009).

In particular, simulation consortia have provided opportunities for collaboration between education and practice institutions as they strive to educate and validate competency of health care professionals. For example, workforce, patient safety, and regulatory pressures have driven the state of Oregon to create a large-scale simulation-based education implementation that uses simulation in training across disciplines (Seropian et al., 2006). Furthermore, centralized efforts and shared resources, both of which are offered through consortia, actually facilitate the implementation of simulation (Seropian et al., 2006). The $\mathrm{ECO}_{15}$ Consortium has allowed stakeholders to contribute to the growth and development of simulation and has positively increased the number of simulation encounters per month, with an average of 310 participants per month in simulation activities throughout the region.

The current gap in literature concerning simulation consortia indicates a need for further research and documented evidence of consortium benefits. It is expected that simulation consortia will continue to develop because of the benefits associated with collaboration and networking. Challenges in education and health care will stimulate formation of groups with common needs to partner in an effort to maximize their resources.

\section{Faculty Development for Simulations}

A review of the literature clearly documents the expanded use and benefits of simulation in nursing education. However, few authors have described proven techniques to encourage faculty participation and development. Barriers to the use of this technology, as described by Jansen, Johnson, Larson, Berry, and Brenner (2009), include time; training; disinterest; lack of space, equipment, or scheduling; funding; staffing; and student engagement. Jones and Hegge (2007) analyzed support systems that faculty 
perceived to be helpful in integrating high-fidelity simulation into the nursing curriculum. These support systems include release time from teaching, collaboration with colleagues, a simulation committee, and simulation workshops. A survey by Adamson (2010) also identified comprehensive training, individual initiative, support from colleagues and administrators, and incentives as ways of improving use of simulation technology.

Of the various methods of faculty development identified by a number of authors, such as workshops, hands-on demonstrations, active learning, networking, and simulation champions, active learning was the favored method for acquiring skills. Jansen et al. (2009) proposed using simulations immediately after training and networking with others to share scenarios and resources as methods to overcome identified barriers. A survey by Anderson, Bond, Holmes, and Cason (2011) identified the most helpful ways to learn about simulation: simulation specialists, demonstrations, workshops, and practice with feedback from others skilled in simulation. Faculty development should extend beyond a one-time offering and include hands-on learning. Although Web sites such as the Simulation Innovation Resource Center are available online for individual training (Jeffries, 2009), collaboration and networking with others enhance programs and allow for those knowledgeable in simulation to share their expertise through either face-to-face meetings or video conferencing (Jansen, Johns, Larson, Berry, \& Brenner, 2009; Kuhrik, Kuhrik, Rimkus, Tecu, \& Woodhouse, 2008). Rothgeb (2008) and Jeffries (2008) also recommend networking with those knowledgeable in integration of simulation into education.

A number of authors have emphasized the concept of a simulation champion or expert. This support system seems crucial to the effectiveness of a simulation program. Conrad, Guhde, Brown, Chronister, and Ross-Alaolmolki (2011) identified faculty champions as motivational leaders who build teams through hands-on education and promote independence in designing and implementing scenarios. The simulation champion would support other faculty members in developing their skills in simulation development and use (Anderson et al., 2011; Griffin-Sobel, Acee, Sharoff, Cobus-Kuo, WoodstockWallace, \& Dornbaum, 2010; Jansen et al., 2009; Jones \& Hegge, 2007). Key elements include sharing the vision, building a team, and providing support to the development of that team (Conrad et al., 2011). Jeffries (2008) identified the steps to improving the use of simulation as using standardized materials, training a trainer, encouraging development of a simulation team, and planning coordination of simulation efforts. Griffin-Sobel et al. (2010) described the benefits of a transdisciplinary-group approach to incorporating simulation into education. 
Dedicated and properly trained experts can provide hands-on instruction in ways to incorporate simulation into nursing education. Encouragement and support through continuing education and financial remuneration contribute to increased use of simulation technology. Integration of simulations into a curriculum is more likely to occur after faculty members have been trained.

\section{Overview of Professional Development in Simulation for the $\mathrm{ECO}_{15}$ Consortium}

The consortium predicated its professional development plan on a needs assessment that established a baseline of current educational requirements and viable equipment. With this information, the consortium designed an initial strategy that included deliberate planning of each task force member's education and a strong collaborative communication strategy. The professional development plan also included a monthly evaluation submitted by each practice partner (hospital and academic stakeholders of the consortium). The evaluation would include the number of participants in simulation-enhanced learning, as well as a description of the experiences and lessons learned. The overall plan focused on filling consortium stakeholders' immediate educational gaps in simulation education theory and established regular meetings to review progress and discuss expansion of the professional development plans. Various assessment and educational activities are described in the following sections.

\section{Needs Assessment}

Before investing financial resources, materials, and time, the consortium conducted a needs assessment to establish a baseline of current educational requirements and viable equipment. One of the first assignments the consortium asked of the consultant was to gather an inventory of current simulation equipment and usage from each of the participating organizations. This information provided data for an assessment of the educational gaps and redundancies in the region's simulation education programs. In fact, the list proved to be somewhat erratic and inconsistent across the organizations, and the main uses of the equipment were basic life support and advanced life support training, not simulation. Each organization also completed a detailed list of simulation equipment and resource needs that included the objectives of the organization, an education plan, equipment needed, and projected costs. Completing the needs assessments allowed project leaders to make educated decisions and allocate appropriate funds where they were most needed.

\section{Consultant}

Clinical simulation is on the cutting edge of clinical education. Research studies are limited, and few evidence-based practices are available. In this case, the project leaders, who were novices in the area, 
acknowledged the need for a consultant with knowledge, expertise, and experience to help lead the task force. They hired an expert in clinical simulation, whose oversight and forward thinking gave the project structure and kept the task force focused on learning about and implementing clinical simulations across the consortium in a timely and efficient manner.

\section{Education for Task Force Members}

Although many of the task force members were classified as novices in clinical simulation, some were at the advanced beginner and competent stages. The leadership of the task force recognized the substantial educational gap, and in order to provide the evidence-based standard needed to bring everyone up to speed, the leadership purchased user licenses for all task force members to access the Simulation Innovation Resource Center and National League for Nursing (NLN) courses (www.nln.org). These sites and online courses were significant in equipping the group with the basic framework to create, develop, and execute a clinical simulation. The professional development plan included the opportunity for consortium members to access these 11 NLN simulation courses:

- Designing and Developing Simulation

- Debriefing and Guided Reflection

- Guidelines for Simulation Research

- Teaching and Learning Strategies

- Integrating Concepts

- Evaluating Simulations

- Curriculum Integration

- Programming a High-Fidelity Simulator

- Designing a Simulation Center

- Maximizing Realism

- Developing Faculty

The task force attended a 3-day interactive workshop with the consultant. The agenda for the 1st day included developing group skills in designing simulations, integrating simulations into nursing curricula and orientations, and basic programming of a medium-fidelity simulator. Day 2 focused on evidencebased research on the use of simulation, the art of debriefing, and basic programming on a high-fidelity simulator. On the final day, all participants had the opportunity to run their simulation and conduct debriefing with real students recruited for the activity. Throughout the workshop the participants 
worked in three subgroups organized according to their clinical expertise. Simulations were written with the standardized template provided by the consultant and included objectives, demographics, medical history, roles, equipment, scripting, and timelines. After performing the simulations, local nursing students received debriefings from each subgroup. The consultant provided group members with feedback on the content and objectives of each simulation and on their debriefing skills.

\section{Webinars}

To continue their professional development, the consortium members asked the consultant to develop educational webinars that could accommodate various busy schedules as well as time and financial constraints. The initial webinar was held in the first quarter of 2010. The webinars, which continue to this day, offer members opportunities to share questions, improve communication, and promote consortium relationships. They encourage strong group discussions and a convenient way to participate.

\section{Quarterly to Biannual Meetings}

The task force has met quarterly since the inception of the consortium in July 2008. Quarterly meetings have proved critical to the success of the consortium because the meetings keep the participants active and engaged in the work. As implementation occurred and each simulation site became more autonomous, the group began meeting biannually to review the professional development plan's progress and address issues.

\section{Outcomes for the Professional Development Initiative}

The consortium created its professional development plan to prepare practitioners to develop safe, quality health care delivery models through the use of high-fidelity simulation and promote collaboration in education across the region. To date, 14 organizations are participating in the consortium. They represent academia $(N=5)$, clinical practice $(N=7)$, and secondary education $(N=2)$. Based on the needs assessment of the partners, 10 simulation labs were built or renovated to incorporate high-fidelity simulation to accommodate the educational needs within each organization. In two cases, simulation laboratories were built in partnerships between schools of nursing and hospital professionals, resulting in shared simulation space. During the past 2 years, 32 nursing educators have completed the relevant NLN simulation courses for their individualized needs.

The consortium aimed to engage 100 participants per month in learning experiences enhanced through simulations. Ten simulation labs were completed in November 2010, when site reporting and data 
collection began. Since completion of the simulation laboratories at each of the practice sites, we have exceeded that goal by 466 participants in postsecondary education and 423 participants in the hospital setting (see Table 1 and Figure 2). To date, more than 2,600 people across the region have participated in simulation learning encounters, exceeding the original goal of 1,600 participants.

\section{Trained Simulation Professionals}

To sustain the partnership within the consortium, the educators and practice professionals who were trained in simulations continue to meet and receive professional development at a higher level.

Between 2009 and 2010, 60 educators and practicing nurses attended simulation workshops and received training beyond the online NLN modules. During the simulation workshops, participants had hands-on experience working with the manikins and collaborating with partner "superusers" from practice and education. These collaborations ultimately resulted in 10 consortium-created and tested scenarios, along with programming for high-fidelity simulators. The trained consortium professionals continue to meet quarterly and biannually through webinars to identify learning and professional development needs.

\section{Early Childhood Exposure}

The consortium has realized the potential of simulation technology as a means to introduce children in kindergarten through Grade 12 to a variety of health care careers. Given that the region consists primarily of rural communities, it is important to recruit and retain health care professionals. As a result, the consortium now partners with the East Indiana Area Health Education Center to create and support strategies that ensure the region will have a future workforce in the health professions. The partners share the following objectives:

1. Informing local $\mathrm{K}-12$ students about health careers.

2. Training students by promoting local clinical experiences for students in health professions.

3. Retaining students through support for continuing education for rural health professionals.

Consistent with these goals, in the first 6 months that partner simulation laboratories were open, 5,000 students from across the region participated in the simulation labs and simulation methodology. Of these visitors, 4,000 were students in grades K through 12 . Students have participated in career 
awareness events and activities involving exposure to health care occupations and the use of simulation technology. Use of high-fidelity manikins, such as the wireless Laerdal $3 \mathrm{G}^{\circ}$, allows students in rural areas of the region to have access to the same opportunities as students in urban areas.

\section{Other Benefits}

The Southeast Indiana Healthcare Simulation Network has also reported positive outcomes, including the following:

- New nursing graduates received enriching experiences in employee orientation that reduce the time to achieve higher levels of performance and confidence.

- Reports of simulation usage by the network indicate that students are becoming more confident and excited about learning through simulation.

- Members of the network routinely share promising practices with each other and learn together through joint professional development opportunities.

- Working together in teams to develop common simulation scenarios reduces the time to develop scenarios and avoids duplication of effort.

- The established support system allows educators to help each other when problems arise or innovations are created.

The ultimate goal is to improve overall knowledge and skills so that the network can provide a higher quality of patient care and safety for its citizens. Measuring and tracking these outcomes will be discussed among the consortium members so that evidence of the consortium's benefits can be demonstrated.

Over the past 2 years, the consortium has focused primarily on developing collaborative simulation laboratories and professional development for the trained simulation professionals within each organization. It has created a systematic evaluation plan for developing a network to promote quality improvement and continued education for nursing students and practitioners in the region. By targeting key imperatives for the region's health care delivery systems, such as developing a professional development plan, the evaluation plan allows results and benchmarks to be tracked and successes and gaps to be identified for further investigation. 


\section{Summary}

In today's tumultuous yet results-based health care environment, consortia help individual organizations to develop strategic plans and meet goals that will transform clinical education. Simulation education prepares new nurses, keeps practicing nurses current, and evaluates clinical competencies required of health professionals. By encouraging innovative thinking and collaborations within and outside the partner organizations, simulation consortia have the potential to ultimately improve patient care.

Consortium partners continue to share the lessons learned in using simulations. The monthly reporting of the partners documents the following lessons learned:

- A learning curve exists, but as simulation practitioners allocate regular time to practice, confidence and competence in using the new pedagogy increases.

- Orientation to the equipment and the pedagogy help to prepare learners for the simulation experience.

- Debriefing sessions with a small number of learners demonstrated more interaction among the instructor and learners, as indicated by the amount of discussion.

- Opportunities for students to participate in a variety of roles within a simulation increase the learning experience.

- Tracking the number of scenarios run, participants trained in the consortium, and other activities demonstrates the progress for school and hospital administrations.

- Tours of the simulation center provide a valuable source of learning for other staff members and the community at large and encourage their support. 


\section{Authors}

Pamela R. Jeffries, PhD, RN, ANEF, FAAN is with John Hopkins University School of Nursing, Baltimore, MD 21205, USA; Jim Battin, BS, is with Strategic Consulting Group, Inc., Columbus, IN 47201, USA; Michelle Franklin, RN, MSN, is with Decatur County Memorial Hospital, Greensburg, IN 47240, USA; Rhonda Savage, MPH, BS, BA, is with East Indiana Area Health Education Center, Batesville, IN 47006, USA; Hollace Yowler, MSN, RN, is with Ivy Tech Community College, Madison, IN 47250, USA; Caroline Sims, RN, Doctoral Candidate, is with Columbus Regional Hospital, Columbus, IN 47201, USA; Tamara Hall, MSN, RN, is with Ivy Tech Community College, Madison, IN 47250, USA; Shelly Eisert, MSN, MHA, RN, CNE, is with Ivy Tech Community College, Lawrenceburg, IN 47025, USA; Cynthia Lauber, MSN, RN, FNP is with Ivy Tech Community College, Madison, IN 47250, USA; Stephanie Brown, Med, BSN, RN, CPN, is with Ivy Tech Community College, Lawrenceburg, IN 47025, USA; Karen Werkskey, BSN, RN, CNOR, is with Schneck Medical Center, Seymour, IN 47274, USA; Rebecca J. Bartlett Ellis, RN, Doctoral Candidate is with Indiana University School of Nursing, Indiana University-Purdue University Columbus, Columbus, IN 47203, USA; Terri Everage, RT, is with St. Vincent Jennings Hospital, North Vernon, IN 47265, USA; Laurie Dorsey, MSN, RN, is with Ivy Tech Community College, Madison, IN 47250, USA.

Corresponding author: pjeffri2@son.jhmi.edu (P.R. Jeffries) 


\section{References}

Adamson, K. (2010). Integrating human patient simulation into associate degree nursing curricula: Faculty experiences, barriers, and facilitators. Clinical Simulation in Nursing, 6, e75-e81. doi:10.1016/j.ecns.2009.06.002.

Anderson, M., Bond, M. L., Holmes, T. L., \& Cason, C. L. (2011). Acquisition of simulation skills: Survey of users. Clinical Simulation in Nursing, 8(2), 59-65. doi:10.1016/j.ecns.2010.07.002.

Articola, C. (1998). The growth and development of an educational consortium. Journal of Continuing Education in Nursing, 29(3), 112-116.

Conrad, M., Guhde, J., Brown, D., Chronister, C., \& Ross-Alaolmolki, K. (2011). Transformational leadership: Instituting a nursing simulation program. Clinical Simulation in Nursing, 7, e189e195. doi:10.1016/j.ecns.2010.02.007.

Griffin-Sobel, J. P., Acee, A., Sharoff, L., Cobus-Kuo, L., Woodstock-Wallace, A., \& Dornbaum, M. (2010). A transdisciplinary approach to faculty development in nursing education technology. Nursing Education Perspectives, 31, 41-43.

Indiana Workforce Development. (2005, January 17). Strategic Skills Initiative (SSI). PowerPoint presentation at the State Human Resource Investment Council quarterly meeting. Retrieved February 22, 2012, from http://www.in.gov/dwd/files/shric_SSI_summary_state_WIB.pdf.

Jansen, D. A., Johnson, N., Larson, G., Berry, C., \& Brenner, G. H. (2009). Nursing faculty perceptions of obstacles to utilizing manikin-based simulations and proposed solutions. Clinical Simulations in Nursing, 5, e9-e16. doi:10.1016/j.ecns.2008.09.004.

Jeffries, P. R. (2008). Getting in S.T.E.P. with simulations: Simulations take educator preparation. Journal of Nurse Educator Perspectives, 29(2), 70-73.

Jeffries, P. (2009). Dreams for the future for clinical simulation. Journal of Nurse Educator Perspectives, $30(2), 71$.

Jones, A. L., \& Hegge, M. (2007). Faculty comfort levels with simulation. Clinical Simulation in Nursing, 3(1), e15-e19. doi:10.1016/j.ecns.2009.05.034.

Kost, M., Wildgust, B., \& Woods, J. (2010). A model for utilization of academic resources: The Philadelphia Area Nurse Anesthesia Education Programs' shared curriculum consortium. AANA Journal, 78(1), 14-17.

Kuhrik, N. S., Kuhrik, M., Rimkus, C. F., Tecu, N. J., \& Woodhouse, J. A. (2008). Using human simulation in the oncology clinical practice setting. Journal of Continuing Education in Nursing, 39(8), 345-355.

Mass, M. L., Conn, V., Buckwalter, K. C., Herr, K., \& Tripp-Reimer, T. (2009). Increasing nursing faculty research: The lowa gerontological nursing research and regional research consortium strategies. Journal of Nursing Scholarship, 41(4), 411-419.

Nickitas, D. M. (2008). The road to the summit: An invitation to build strategic partnerships no matter where you sit. Nursing Economic\$, 26(5), 293.

Rothgeb, M. K. (2008). Creating a nursing simulation laboratory: A literature review. Journal of Nurse Education, 47(11), 489-494.

Seropian, M. A., Driggers, B., Taylor, J., Gubrud-Howe, P., \& Brady, G. (2006). The Oregon simulation experience: A statewide simulation network and alliance. Simulation in Healthcare, 1(1), 56-61.

Tornabeni, J., \& Miller, J. F. (2008). The power of partnership to shape the future of nursing: The evolution of the clinical nurse leader. Journal of Nursing Management, 16, 608-613. 


\section{Tables}

Table 1. Simulation Usage per Month (November 2010-June 2011)

\begin{tabular}{|c|c|c|c|c|c|c|c|c|}
\hline \multirow[t]{2}{*}{ Organization and goal overview } & \multicolumn{8}{|c|}{ Number of Participants } \\
\hline & Nov. & Dec. & Jan. & Feb. & Mar. & Apr. & May & June \\
\hline Postsecondary education & 100 & 64 & 84 & 188 & 132 & 251 & 247 & 34 \\
\hline Goal & 100 & 100 & 100 & 100 & 100 & 100 & 100 & 100 \\
\hline Accumulative actual vs. goal & 0 & -36 & -52 & +36 & +68 & +219 & +466 & +400 \\
\hline Hospitals & 170 & 124 & 118 & 136 & 143 & 281 & 141 & 269 \\
\hline Goal & 100 & 100 & 100 & 100 & 100 & 100 & 100 & 100 \\
\hline Accumulative actual vs. goal & +70 & +94 & +112 & +158 & +201 & +382 & +423 & +592 \\
\hline
\end{tabular}




\section{Figures}

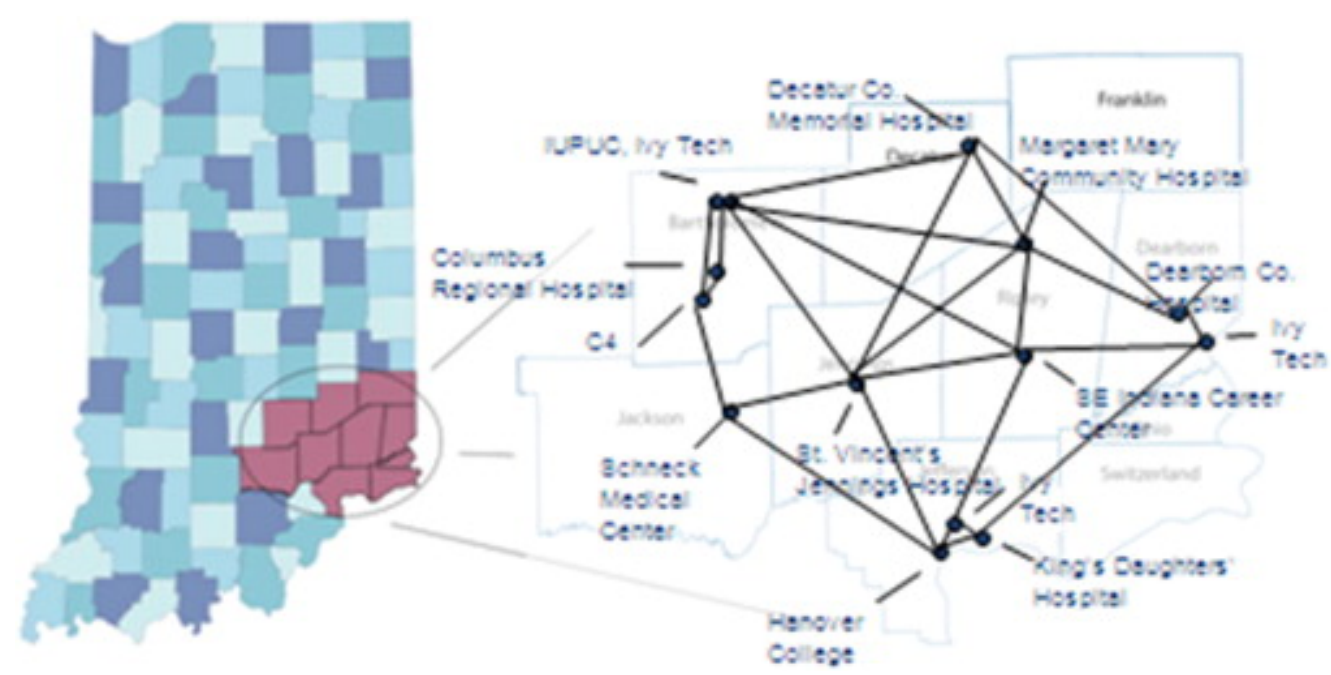

Figure 1. Southeast Indiana Health Care Simulation Network Hospitals: Columbus Regional Hospital, Dearborn County Hospital, Decatur County Memorial Hospital, King's Daughter's Hospital and Health Services, Margaret Mary Community Hospital, Schneck Medical Center, and St. Vincent's Jennings County Hospital. Education: Columbus Area Career Connection (C4), Hanover College, Indiana University-Purdue University Columbus, Ivy Tech Columbus, Ivy Tech Lawrenceburg, Ivy Tech Madison, and Southeast Career Center.

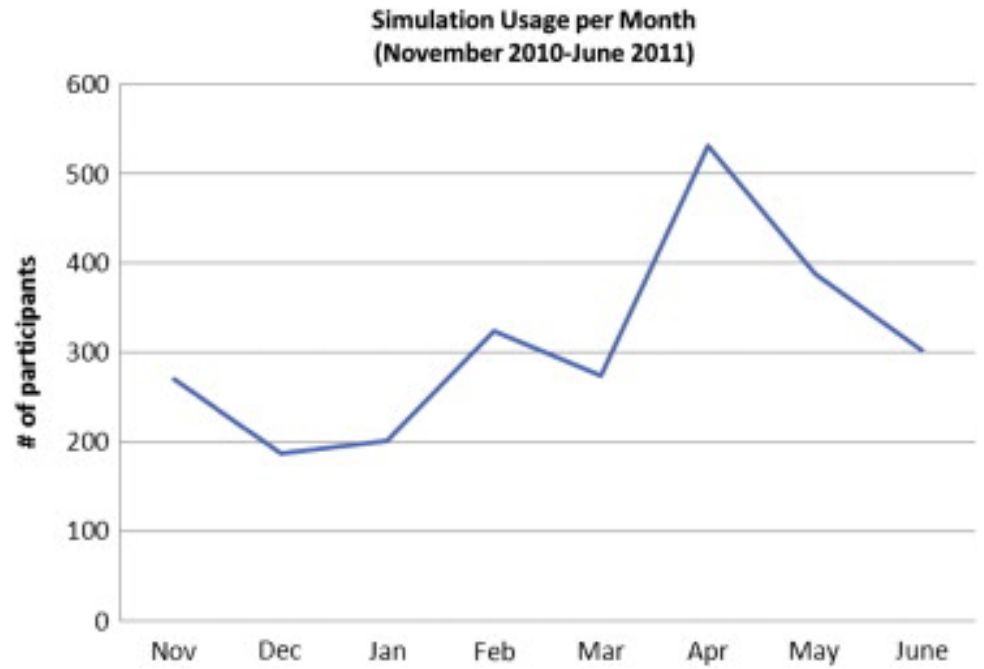

Figure 2. Simulation usage per month (November 2010-June 2011) by the consortium. 